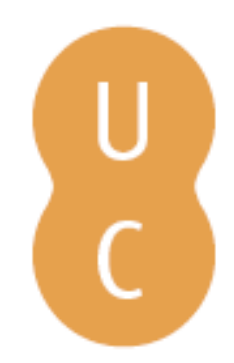

\title{
pommalina
}

\section{Duas aristocratas no convento: as autobiografias de Antónia Margarida de Castelo Branco e da Marquesa de Alorna}

\author{
Autor(es): $\quad$ Rocha, Clara
}

Publicado por: Imprensa da Universidade de Coimbra

URL

persistente: URI:http://hdl.handle.net/10316.2/38684

DOI: $\quad$ DOI:http://dx.doi.org/10.14195/978-989-26-1164-8_7

Accessed : $\quad$ 26-Apr-2023 11:25:00

A navegação consulta e descarregamento dos títulos inseridos nas Bibliotecas Digitais UC Digitalis, UC Pombalina e UC Impactum, pressupõem a aceitação plena e sem reservas dos Termos e Condições de Uso destas Bibliotecas Digitais, disponíveis em https://digitalis.uc.pt/pt-pt/termos.

Conforme exposto nos referidos Termos e Condições de Uso, o descarregamento de títulos de acesso restrito requer uma licença válida de autorização devendo o utilizador aceder ao(s) documento(s) a partir de um endereço de IP da instituição detentora da supramencionada licença.

Ao utilizador é apenas permitido o descarregamento para uso pessoal, pelo que o emprego do(s) título(s) descarregado(s) para outro fim, designadamente comercial, carece de autorização do respetivo autor ou editor da obra.

Na medida em que todas as obras da UC Digitalis se encontram protegidas pelo Código do Direito de Autor e Direitos Conexos e demais legislação aplicável, toda a cópia, parcial ou total, deste documento, nos casos em que é legalmente admitida, deverá conter ou fazer-se acompanhar por este aviso.

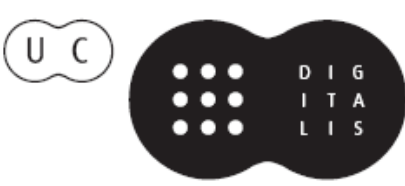


Clara Rocha

Universidade Nova de Lisboa

\section{DUAS ARISTOCRATAS NO CONVENTO: AS AUTOBIOGRAFIAS DE ANTÓNIA MARGARIDA DE CASTELO BRANCO E DA MARQUESA DE ALORNA}

O que podem ter em comum duas narrativas tão diversas e tão distantes no tempo como a Autobiografia de Antónia Margarida de Castelo Branco ${ }^{1}$ e a "Autobiographie" de D. Leonor de Almeida Portugal, Marquesa de Alorna²? Escritas por aristocratas que, contra a sua vontade, passaram uma parte importante das suas vidas no convento, as duas autobiografias relatam o percurso de duas mulheres afastadas do mundo por força de condicionalismos familiares e profundamente marcadas por um destino de adversidade e de sofrimento. Mas, para além da circunstância biográfica - a clausura forçada - que os determina, que outras afinidades haverá entre esses dois textos, o primeiro saído da pena de uma mulher sem pretensões literárias, que recorda o casamento infeliz como episódio nuclear da sua vida, e o segundo redigido em francês, ainda na juventude, por aquela que se tornaria uma das mais importantes figuras da cultura portuguesa do século xvıI? Apesar das experiências pessoais tão diversas e das mundividências epocais que lhes dão lastro, as duas autobiografias obedecem a um mesmo princípio, o da objectivação dum trauma como etapa fundamental num processo de auto-análise, de autocompreensão e de consolidação duma identidade temporária ou definitivamente ameaçada pelo sofrimento. E ambas evidenciam o potencial catártico e (re)estruturante da escrita autobiográfica,

\footnotetext{
1 Antónia Margarida de Castelo Branco, Autobiografia, prefácio e transcrição de João Palma-Ferreira, Lisboa, IN-CM, 1984.

2 Marquesa de Alorna, "Autobiographie", in Inéditos. Cartas e Outros Escritos, selecção, prefácio e notas do Prof. Hernâni Cidade, Lisboa, Livraria Sá da Costa Editora, 1941.
} 
entendida não apenas como exercício de rememoração do vivido mas, sobretudo, como indagação em torno dos interesses e valores fundadores duma existência. Em ambas, o 'eu' que se revolta contra os lances do destino é também um ser que se perscruta, se decifra e desse modo se fortalece. Ao avivar por meio da escrita as alegrias e as tristezas, as ilusões e as feridas, as motivações e as contingências da sua vida, o 'eu' autobiográfico reconstitui a sua forma própria e, colocando o trauma em perspectiva, refaz a consistência e a significação do seu percurso pessoal. Tanto a autobiografia de Antónia Margarida de Castelo Branco como a de D. Leonor de Almeida são representações literárias dum processo de formação - intrincado e cheio de escolhos no caso da religiosa de Xabregas, que na sua vida conventual encarna ainda as inquietações dum espírito barroco, claro e bem definido no caso da jovem Alcipe, que cedo assumiu a sua vocação de femme de lettres e dela faz o cerne do seu breve relato autobiográfico. Por outras palavras, são "autobiografias espirituais", em que o alinhamento dos dados factuais conta muito menos do que o retrato do amadurecimento ou aperfeiçoamento duma personalidade, e cuja finalidade é a apreensão essencialista dum 'eu' na sua dimensão moral ou na sua singularidade intelectual e artística.

Com o título Relação (fiel e verdadeira) que dá dos sucessos da sua vida, a criatura mais ingrata ao seu criador, a autobiografia de Antónia Margarida de Castelo Branco foi redigida durante longos anos, de 1681 a 1703, e constitui um impressivo testemunho pessoal, bem como um notável documento sobre a vida secular e conventual do século xvir português. Antónia Margarida nasceu em 1652 na vila do Lavradio, no seio de uma família nobre, e casou-se em 1670, por escolha de sua mãe, com Brás Teles de Meneses, um fidalgo arruinado e marialva, que a sujeitou a constantes maus tratos e humilhações. Durante oito anos sofreu com resignação as cenas de ciúmes e as agressões do marido, vendo nelas tentações do demónio, mas acabou por pedir o divórcio e por ingressar no convento em 1679. As leis da época permitiam à mulher, cujo marido cometesse "adultério público", recolher-se a uma instituição religiosa e professar ordens. Dessa forma entrou Antónia Margarida no convento de Santos, onde aguardou a sentença de divórcio, e depois no convento de Xabregas, onde passou o resto dos seus dias, sempre atormentada e dividida entre os escrúpulos de consciência e os êxtases místicos. A sua narrativa de vida é a história dum permanente conflito interior: enquanto jovem esposa, viveu martirizada pelas 
obsessões doentias do marido; na sua entrega a Deus, que se consumou mais por condenação do que por vocação, também nunca chegou a apaziguar as suas mágoas e inquietações.

Ao longo de mais de vinte anos, Antónia Margarida redigiu a sua autobiografia, como sucedeu aliás com outras religiosas portuguesas do século xvir e de inícios do século xviII. Fê-lo em obediência ao seu director espiritual, Frei Filipe de Santiago, e mais do que uma vez expressou o desejo de pôr termo a esse penoso exercício. O seu segundo confessor, Frei João de Santo Estêvão, não lhe consentiu que queimasse os cadernos entretanto escritos e intimou-a a prosseguir o relato. Como faz notar João Palma-Ferreira no prefácio à edição da Autobiografia, no quadro da vida conventual seiscentista a imposição da prática autobiográfica era, na realidade, uma forma de vigilância e de censura. Graças a ela, os padres confessores exerciam um exame constante sobre a fidelidade das religiosas aos votos, ao mesmo tempo que as obrigavam a revelar aspectos da sua vida íntima e familiar. Depois da morte do seu segundo director espiritual, Antónia Margarida de novo sentiu o impulso de destruir os cadernos, como regista no último capítulo da autobiografia. Mas recordando a recomendação que o seu confessor lhe fizera de que não queimasse os papéis, e também em obediência às ordens do Padre Provincial, decidiu-se a retomar a pena e a concluir aquilo a que chama "este livro", confiando o destino do seu escrito à providência divina:

Sua divina Majestade seja servido de aceitar a mortificação com que finalizo este livro, ignorando que fim terá, pois, ao presente, não tenho tenção de que ninguém o veja senão quem for guia de minha alma e como não sei o que Deus quer, não me sei determinar mais que a fiar sempre mais e mais na sua providência amorosa ${ }^{3}$.

A primeira parte da Autobiografia relata a vida secular de Antónia Margarida de Castelo Branco: a linhagem, a infância e o casamento mal sucedido como episódio nuclear da sua existência. A segunda parte, muito mais extensa, narra o ingresso no convento e a entrega à vida religiosa, com as suas macerações e

3 Antónia Margarida de Castelo Branco, op. cit., p. 524. 
contradições, as constantes dúvidas e os fugazes momentos de plenitude. De índole mais propriamente contemplativa, esta segunda parte da autobiografia é um exemplo de literatura da "experiência de Deus", inspirada nas obras de Santa Teresa de Ávila e de S. João da Cruz. A autora menciona, aliás, os dois místicos espanhóis, cuja leitura lhe fora aconselhada pelo seu confessor. Há uma evidente desproporção entre a primeira parte da narrativa, que ocupa trinta e seis capítulos, e a segunda, que se estende ao longo de mais de cem. Mas compreende-se que assim seja, dadas as circunstâncias e as motivações da redacção do texto.

A parte do relato que diz respeito à vida profana é, sem dúvida, a mais viva e pitoresca. Rememora as cenas marcantes duma infância e juventude destinadas ao infortúnio, e documenta aspectos vários da vida social do século XVII, como os mecanismos reguladores do casamento (casamentos ajustados, contratos pré-nupciais, processos de separação) ou o quotidiano duma família nobre numa quinta nos arredores de Lisboa. Com orgulho de classe, Antónia Margarida começa por referir o seu berço e os seus ancestrais, evocando em seguida as vicissitudes da meninice, as mortificações que sofreu, a morte do pai e o modo traumático como recebeu a notícia do seu próprio noivado:

Eu estava ignorante de tudo e vendo falar segredos aos de casa, perguntei o que era e respondeu uma criada: "Minha senhora, isto é quererem-na casar com um homem que não tem mais que sangue: é muito nobre, muito pobre e muito terrível."

À vista desta informação, fiquei tão assustada que posso dizer que foi a primeira coisa que me fez abalo no coração, crendo que Deus havia permitir se efectuasse aquele negócio só por meu castigo; e por esta causa ia observando todos os sucessos, tendo-os por anúncio do que havia suceder ${ }^{4}$.

Descreve depois a cerimónia do casamento, com pormenores que traem a sensibilidade feminina de quem escreve:

4 Ibid., p. 83. 
Sendo eu sempre naturalmente mui corada e quando falava ou me via diante de muita gente costumava corar mais, no instante que dei a mão para receber-me, escoei de sorte que parecia de pedra ou que tinha levado muitas sangrias 5 .

A narrativa autobiográfica prossegue com o retrato de Brás Teles de Meneses, marido violento, maníaco e oportunista, que usa o dote da mulher para pagar as dívidas e chega ao ponto de, à mesa, lhe atirar as amêijoas do jantar, ferindo-a no rosto, ou mesmo de sadicamente lhe tirar a comida para a dar aos cães:

(...) Algumas vezes com inconsiderada impiedade vinha a horas de jantar e repartia tudo pelos cães e eu e os pobres criados ficávamos em jejum. Eu o levava por mercê de Deus, com paciência, louvando o Senhor pelo que dava àqueles moços, pois nada os fazia arrepender de me assistirem obrigados do amor de criação, que tinham sido pajens de minha Mãe, de muito pequenos, e eram bem procedidos e por me serem companheiros nestes trabalhos lhe(s) devo grandes obrigações ${ }^{6}$.

Noutras passagens, a narradora conta as alucinações do marido, a quem o demónio aparecia na forma de vultos de hipotéticos rivais, que perseguia com a sua espada nua.

Na segunda parte da Autobiografia, o ritmo da narrativa perde em dinamismo, e o texto passa a incidir sobre a vida espiritual da mulher dedicada ao amor de Deus, com os seus êxtases místicos e os seus momentos de incerteza e de descrença. A consolação de alma associada à entrada no convento, o recentramento do 'eu' no seu novo espaço e modo de vida (não falta no capítulo 53 a referência ao centro do mundo, como forma de ancoragem da identidade que a tradição literária autobiográfica largamente cultivou), mas também as doenças e os padecimentos sofridos, os escrúpulos de consciência e a procura da entrega total a Deus são os principais tópicos desta parte do texto. Esta segunda parte tem ainda um valor documental, retratando o quotidiano da vida conventual seiscentista, a distribuição dos serviços religiosos, a presença forte do confessor, as práticas médicas, as festividades e os usos gastronómicos ligados a certos

\footnotetext{
Ibid., p. 86.

6 Ibid., p. 142.
} 
momentos do calendário. Mas a autodisciplina duma natureza inquieta e o exercício de purificação espiritual são as preocupações obsessivas da narradora, que entende a prática autobiográfica como um exercício de autognose:

Enfim, Senhor, eu não quero penetrar os vossos juízos porque fora atrevimento; o que só quero é conhecer o que sou e o que vos devo a vós?.

Na tentativa de merecer a misericórdia divina, a amargurada freira ora se regozija por conseguir vencer as suas dúvidas, ora se classifica de "monturo", "escória da miséria" e "monstro de pecados"; ora agradece a ajuda de Deus que a fortalece "com actos de fé e esperança", ora deplora a sua "falta de ânimo" e a "tibieza" com que pratica esses actos. Todo o texto, minuciosamente auto-analítico, é configurado por essa permanente oscilação emocional. Umas vezes, a narradora escreve: "cada dia que amanhece me acho pior, mais omissa, mais ingrata e pecadora"; logo adiante, relata-nos os seus "incêndios" de alma, num registo figurado que incorpora as metáforas características da literatura mística:

Outras vezes, pedindo licença para me ficar no coro com impulsos de espírito, me sucedeu negar-me a Prelada e mandar-me deitar e comunicar-se meu Senhor à minha alma no enxergão, com tão amorosos incêndios, que bem se podia dizer então por mim que estava o fogo na palha sem arder?

A narrativa estende-se ao longo dos meses e dos anos, em consequência do próprio desassossego íntimo de quem escreve, mas acaba por encontrar o seu remate no capítulo 140, que reflecte sobre a completude do "livro" escrito no decurso de duas décadas (e finalmente assumido como objecto acabado), e paralelamente sobre a completude duma identidade modelada com a ajuda da providência divina, cujos "efeitos prodigiosos" a autora glorifica:

(...) pois, sendo eu naturalmente tão tímida e irresoluta (como mostro em toda esta relação) vejo-me agora tanto ao contrário que eu mesma me admiro, pois se me infundiu um certo seguro e fortaleza interior tão grande e desapego de tudo o

7 Ibid., p. 183.

8 Ibid.

9 Ibid., p. 249. 
da terra que já me não atemoriza nada mais que o perder a graça de meu Senhor e, tendo-a, não necessito de nada mais ${ }^{10}$.

Muito mais elaborada do ponto de vista literário é a autobiografia da Marquesa de Alorna, parcialmente publicada por Hernâni Cidade no volume Inéditos. Cartas e Outros Escritos. Escrita ainda na juventude, é uma narrativa breve e cuidadosamente construída, que nos dá uma visão retrospectiva e englobante da primeira fase da vida da autora e uma síntese forte da sua personalidade. Reportando-se aos anos passados no Convento de Chelas com a mãe e a irmã, é um testemunho que de certo modo decalca e reforça o retrato autobiográfico plasmado na intensa correspondência que a jovem Alorna manteve com o pai, também ele preso no Forte da Junqueira por ordem do Marquês de Pombal. Nessa correspondência diária e clandestina, D. Leonor relata o quotidiano no convento, os seus estudos e os progressos da sua formação intelectual. As luzes e a cultura do espírito são, como repetidas vezes explicita, o seu ideal de beleza interior e de perfeição. As leituras, as lições de francês, italiano e latim, os exercícios de tradução dos clássicos, as composições poéticas, o canto, a conversação e, naturalmente, a actividade epistolar são o ritual diário desse aperfeiçoamento. Só muito raramente vem à tona nas cartas o lado frívolo da rapariga, como na missiva em que descreve ao pai o modo como foi festejado o aniversário da irmã e lhe conta como estreou um vestido cor de laranja e se enfeitou com outros adornos, "sem excesso mas de modo que o espelho me não deixasse mal comigo", concluindo com uma reflexão irónica sobre a própria coquetterie:

Eu não sei como chame a um acto do nosso entendimento feminino, que à vista de uma imagem menos feia, tem a habilidade de pôr a alma toda na corneta no espartilho nos laços etc. ${ }^{11}$.

Pelo exercício introspectivo, D. Leonor vai também delineando os traços de uma personalidade em formação, revelando a D. João de Almeida as contradições do seu ser, ora risonho ora mal-humorado, ora paciente ora inconformado, ora pragmático ora idealista, e espantando-se como "num só dia muda a gente de

\footnotetext{
$10 \quad$ Ibid., p. 524.

11 Carta inédita da Fundação das Casas de Fronteira e Alorna.
} 
carácter vinte vezes"12. Alguns esboços psicológicos são especialmente penetrantes, como aquele em que exprime a sua ânsia de absoluto, confessando que não gosta senão daquilo que não pode ter.

No regime fragmentário atinente ao género epistolar, as cartas da jovem Alorna ao pai compõem o auto-retrato muito vivo duma figura que conjuga de forma singular a vocação erudita e a sensibilidade poética, o espírito das Luzes e o excesso pré-romântico do 'eu'. A sua concisa "Autobiographie", redigida em francês, confirma esse retrato, mas quem escreve é agora a intelectual, que nesses termos se olha e se auto-representa, e não a rapariga que se corresponde com o pai em estilo simples e correntio, expressando-lhe a cada passo a sua submissão, respeito e amor. A personagem autobiográfica é designada pelo pseudónimo Alcipe, que lhe fora dado pelo seu mestre Filinto Elísio, e a narradora utiliza a $3^{\mathrm{a}}$ pessoa gramatical para falar de si, num efeito de desdobramento e de distanciamento que lhe permite vincar a excepcionalidade da figura retratada. Mais tarde, Almeida Garrett utilizaria também a $3^{\text {a }}$ pessoa gramatical numa (auto)biografia publicada em 1843 no tomo III do Universo Pitoresco ${ }^{13}$, uma auto-representação laudatória em que escamoteia a autoria do texto e simula biografar, projectando-se a si mesmo como "uma das maiores notabilidades desta época" nos planos cívico e artístico.

Embora se inicie, de forma convencional, pela referência ao nascimento e aos laços familiares, e prossiga com a alusão às vicissitudes duma infância injustiçada pelo poder arbitrário, a autobiografia da Marquesa de Alorna pouco nos revela sobre os aspectos factuais da sua vida. É muito mais uma "autobiografia espiritual" focada na progressão das suas leituras e da sua formação durante os anos passados no convento:

Alcipe vécut sous les yeux de sa mère et dans la société de sa soeur, sans connoître du monde que les malheurs dont elles étoient victimes et (au long de leurs) jours sereins quoique sombres, elles ne connoisaient d'autre amusement que la lecture et la prière.

C'est dans ce séjour tranquille que la mère s'occupa de former son esprit et son coeur. Dans son coeur elle trouva le germe des grandes passions, qui, dirigé

12 Carta inédita da Fundação das Casas de Fronteira e Alorna.

13 Reproduzida nas Obras Completas de Almeida Garrett, dir. e pref. por Teófilo Braga, 2 vols., Lisboa, 1904. 
dans un but sage, tourne toujours au profit du caractère. Dans son esprit rien ne s'opposait non plus à l'étude des sciences et des arts, et sans d'autres moyens que les livres, les trois solitaires purent comprendre ce que bien souvent on ne peut atteindre au milieu de monde, entouré de maîtres et de modèles ${ }^{14}$.

A autobiógrafa evoca, assim, o seu talento para a poesia e as primeiras composições poéticas que escreveu, inspiradas pelos "objets naturels", bem como a leitura das poéticas e dos poetas latinos, franceses e italianos. Refere a sua "curiosité avide" e o modo como as pessoas que a rodeavam viam nela, ainda que muito nova, "un prodige d'étude et de savoir". Regista a sua necessidade de introspecção e auto-análise ("l'étude de soi même commença à lui devenir nécessaire pour apprécier l'étendue de ses facultés"15) e recorda as várias etapas da sua formação intelectual, sublinhando o modo como o seu espírito crítico pouco a pouco se foi fortalecendo e como a sua "petite raison" deixou de aceitar passivamente as ideias colhidas nos livros. Chega a dramatizar no texto, por meio do monólogo em discurso directo, as suas reflexões e argumentos críticos de leitora juvenil. Frequentadora da obra de Malebranche por indicação da mãe e "malebranchiste à outrance" durante um ano, leu depois Condillac e Locke, Leibniz e Helvetius, e por fim toda a metafísica antiga e moderna. Em seguida passa ao estudo da História Natural, mais tarde interessa-se pela História sagrada e devora os livros de História antiga e moderna. A par dos trabalhos próprios do seu sexo, como o bordado, tornam-se também ocupações predilectas a música e a pintura. Mas a orgulhosa Alcipe traça o retrato impiedoso do seu mestre de música, "qui chantoit bien mais ne sçavoit point ce qu'étoit la musique" e que, como muitos outros, "chantoit par habitude et ignorant que les meilleurs instituteurs de musique sont la Nature, les oiseaux, les vents et les corps sonores, ainsi que la connoissance anatomique de l'organe qui en reçoit l'impression la plus immédiate"16. O seu espírito rebelde e a sua intuição musical fazem-na entrar em conflito com o mestre, recusando o estudo do compasso e passando as lições a discutir.

Outros passos da autobiografia são reveladores do temperamento exaltado desta mulher de letras que a si mesma se descreve como "un coeur sensible et

14 Marquesa de Alorna, Inéditos. Cartas e Outros Escritos, p. 201.

15 Id., ibid., p. 202.

16 Ibid., p. 206. 
une imagination ardente"17. É o caso da passagem em que a narradora refere a doença da mãe e o voto de renúncia que fez ao vê-la tão mal, temerário propósito do qual só ao fim de vinte e seis dias conseguiram demovê-la. E é o caso, também, das páginas em que revela a sua dedicação à cabeceira das freiras doentes e o modo como as tratava e acompanhava os seus últimos momentos, tirando dessas tragédias quotidianas lições sobre a desorganização dos corpos e sobre os efeitos da consciência moral.

A ideia nuclear sobre a qual se constrói a autobiografia da Marquesa de Alorna é a de que "l'hommage le plus pur qu'on peut offrir à la divinité c'est la culture de l'esprit"18. Este texto corporiza assim um exercício de auto-representação que complementa o da correspondência. Mas é uma representação reflectidamente literária, procurando dar a coerência, a superioridade intelectual, o talento e a singularidade de alguém que a si mesma se retrata enquanto artista.

As autobiografias de Antónia Margarida de Castelo Branco e da Marquesa de Alorna são, pois, dois textos que verbalizam um trauma e que reconstituem uma identidade, ameaçada pelo infortúnio e pelo isolamento da vida conventual. São exercícios de catarse e de recentramento, que atestam a importância da reflexão intimista como reserva anímica e como possibilidade de reconstrução de um autos, contra o veneno lento da clausura e da mágoa. Mas entre elas vai toda a diferença que estrema o acto de escrita imposto por outrem e o acto de escrita voluntário, a disciplina obediente e a atitude narcísica, a auto-análise que se dilata ao longo dos meses e dos anos e a auto-representação que busca a essência do 'eu', o uso imediato da $1^{\text {a }}$ pessoa gramatical e o da $3^{\text {a }}$ pessoa enquanto construção mental, a assinatura com o nome próprio e o pseudónimo, a narrativa em extensão e a montagem literária que conduz a uma síntese. Em suma, toda a diferença que situa a "Autobiographie" da Marquesa da Alorna no campo da intenção literária e que confere à personagem de Alcipe a espessura duma existência não só biográfica e textual, mas também, e sobretudo, autoral.

* Por vontade da autora, o presente texto não segue as normas do novo Acordo Ortográfico.

17 Ibid., p. 209.

18 Ibid., p. 211. 